\title{
Desain Merchandise Sebagai Media Penunjang Promosi Pada SMK Insan Madani Kabupaten Tangerang
}

\author{
M. Puad Abdul Baqi ${ }^{* 1}$, Achmad Zainudin M. ${ }^{2}$, Catur Hadi Sadewo $^{3}$ \\ 1,2,3 Jurusan Teknik Informatika, Universitas Raharja Tangerang \\ E-mail: ${ }^{* 1}$ puad@ raharja.info, ${ }^{2}$ zain.mn@ raharja.info,${ }^{3}$ catur.hadi@ raharja.info
}

\begin{abstract}
Abstrak
Perkembangan dunia pendidikan yang semakin pesat, mengharuskan suatu lembaga pendidikan untuk meningkatkan mutu dan kualitasnya, untuk dapat bersaing di tengah masyarakat. SMK Insan Madani adalah sebuah lembaga dalam bidang pendidikan. SMK Insan Madani merupakan sekolah islami yang berlokasi di Perumahan Talaga Bestari, Kecamatan Sindang Jaya, Kabupaten Tangerang, Banten. Setiap tahunnya selalu membuka penerimaan peserta didik baru. Untuk menarik minat calon siswa-siswi baru maka dibutuhkan sebuah Souvenir. Souvenir yang dilakukan menggunakan media komunikasi visual. Media Komunikasi Visual merupakan salah satu bentuk media informasi dan promosi yang mudah dipahami dan dimengerti oleh kalangan luas. Karena itu, penggunaan media komunikasi visual sangat dibutuhkan dalam pengenalan diri sebuah lembaga Pendidikan kepada masyarakat luas. Saat ini media komunikasi visual yang digunakan oleh sekolah hanya menggunakan spanduk, brosur dan Poster. Media Desain komunikasi Visual yang saat ini digunakan sederhana dan informasinya belum update. Maka dari itu dibutuhkan pengembangan media komunikasi visual yang menarik agar bisa menarik minat calon siswa-siswi baru untuk bersekolah di SMK Insan Madani Kabupaten Tangerang. Metode yang digunakan pada penelitian ini adalah field research (penelitian lapangan) dengan melakukan observasi, wawancara dan studi pustaka serta metode perancangan media. Penelitian ini menghasilkan media Merchandise yang digunakan sebagai penunjang promosi pada SMK Insan Madani Kabupaten Tangerang.
\end{abstract}

Kata Kunci-Desain Komunikasi Visual, Merchandise, Media Promosi

\section{Abstract}

The increasingly rapid development of the world of education requires an educational institution to improve its quality and quality, to be able to compete in society. SMK Insan Madani is an institution in the field of education. SMK Insan Madani is an Islamic school located in Talaga Bestari Housing, Sindang Jaya District, Tangerang Regency, Banten. Every year it always opens up new students. To attract new prospective students, a souvenir is needed. Souvenirs are made using visual communication media. Visual Communication Media is a form of information and promotion media that is easily understood and understood by the wider community. Therefore, the use of visual communication media is needed in the self-introduction of an educational institution to the wider community. Currently, the visual communication media used by schools only uses banners, brochures and posters. Media Visual communication design that is currently used is simple and the information has not been updated. Therefore, it is necessary to develop an attractive visual communication media in order to attract prospective new students to attend SMK Insan Madani, Tangerang Regency. The method used in this study is field research (field research) by conducting observations, interviews and literature study as well as media design methods. This research produces media Merchandise that is used to support promotion at SMK Insan Madani, Tangerang Regency.

Keywords - Design Communication Visual, Merchandise, Promotion Media 


\section{PENDAHULUAN}

Promosi adalah salah satu bentuk strategi untuk memperkenalkan suatu produk, jasa atau layanan secara publik agar lebih dikenal secara luas dan menciptakan ketertarikan tersendiri, sehingga dapat memenuhi pencapaian target yang diinginkan. Pada perkembangan teknologi yang semakin pesat seiring berjalannya waktu, menciptakan suatu peluang dimana promosi dapat dibuat dengan berbagai bentuk, salah satunya adalah media promosi berbentuk Merchandise. Teknologi lahir dari pemikiran manusia yang berusaha untuk mempermudah kegiatan-kegiatannya yang kemudian diterapkan dalam kehidupan ${ }^{[1]}$, hal inilah yang membuat peran teknologi sangat efektif untuk digunakan dalam pembuatan media promosi seperti Merchandise. Merchandise adalah bentuk produk yang ditujukan sebagai sarana informasi dan promosi $^{[2]}$, dimana didalamnya terdapat identitas, informasi, maupun fasilitas dan pelayanan yang diberikan oleh suatu instansi atau perusahaan. Dalam dunia Pendidikan, media promosi sangat berperan penting dalam memperkenalkan identitas sekolah, sehingga masyarakat luas khususnya calon siswa/i baru dapat mengenal dan memiliki ketertarikan untuk mendaftar. Banyak sekolah saat ini berusaha membuat media informasi dan promosi semenarik mungkin, salah satunya adalah SMK Insan Madani Kabupaten Tangerang.

SMK Insan Madani Kabupaten Tangerang adalah sekolah swasta yang didirikan pada tahun 2016. Maksud dan tujuan dari pendirian SMK Insan Madani adalah semata mencari Ridha Allah SWT, dengan dasar akhlak mulia, unggul di zamannya, dan terampil dalam berbagai bidang, sehingga siswa/i tamatan dari Yayasan Pendidikan Insan Madani diharapkan mampu bersaing, baik dalam kegiatan keagamaan, kemanusiaan, maupun dalam bidang sosial yang didalamnya termasuk Pendidikan yang berimplikasi kepada dunia kerja. Dalam proses pemasarannya agar lebih dikenal dan diminati oleh banyak orang, saat ini SMK Insan Madani Kabupaten Tangerang hanya menggunakan media desain komunikasi visual sebagai bentuk mempromosikan sekolah ke masyarakat luas seperti spanduk, brosur dan poster dimana media tersebut masih sederhana, informasinya belum update dan kurang memiliki ketertarikan dalam mempengaruhi minat calon siswa/i baru untuk mendaftar di SMK Insan Madani Kabupaten Tangerang. Maka dari itu, perlu adanya pembaruan media promosi yang di desain semenarik mungkin, bervariatif, dan memiliki informasi serta menggambarkan identitas sekolah. Desain adalah suatu cara untuk merancang sesuatu yang sebelumnya sudah direncanakan mengenai struktur dan bentuk yang akan dibuat ${ }^{[3]}$.

Dalam membuat media promosi menjadi lebih menarik, proses desain sangat berpengaruh sangat penting. Dalam hal ini, pengembangan media promosi SMK Insan Madani Kabupaten Tangerang yang dimaksud adalah desain komunikasi visual Merchandise untuk memenuhi kebutuhan konsumen dalam memberikan kesan terbaik tentang fasilitas pendidikan yang diberikan SMK Insan Madani Kabupaten Tangerang ${ }^{[4]}$. Adapun pengembangan desain komunikasi visual yang dibuat antara lain: Spanduk, Mug Gelas, Kalender, Goodie Bag Tali, Jam Dinding, Pin, Stiker, Pulpen, Gantungan Kunci dan Amplop. Melalui desain komunikasi visual berbentuk Merchandise ini diharapkan dapat meningkatkan image positif bagi SMK Insan Madani Kabupaten Tangerang untuk lebih menarik calon siswa/siswi baru.

\section{METODE PENELITIAN}

Pada penelitian ini penulis menggunakan metode field research (penelitian lapangan) yaitu sebuah penelitian langsung dengan cara mendatangi SMK Insan Madani Kabupaten Tangerang selaku tempat penelitian dan melakukan pengumpulan data melalui proses observasi yaitu mengamati situasi dan permasalahan yang dihadapi mengenai penggunaan media informasi dan promosi pada SMK Insan Madani Kabupaten Tangerang, selanjutnya penulis melakukan wawancara terhadap kepala sekolah SMK Insan Madani Kabupaten Tangerang selaku stakeholder untuk mengetahui informasi mengenai perkembangan penggunaan media informasi dan promosi yang digunakan serta untuk mendapatkan informasi tambahan yang nantinya akan di olah menjadi sebuah data yang akurat lalu yang terakhir dari proses 
pengumpulan data adalah studi pustaka dimana penulis melakukan pengumpulan data dengan cara mencari referensi melalui buku dan jurnal ilmiah yang sesuai dengan penelitian ini. Metode yang terakhir adalah metode perancangan media yaitu untuk mengetahui tahapan-tahapan pembuatan media Merchandise serta program komputer yang digunakan sebagai penunjang proses desain seperti melakukan pembuatan Layout desain, pewarnaan desain dan pencerahan desain. Adapun program yang digunakan adalah Adobe Photoshop CC dan Adobe Ilustrator $C C$.

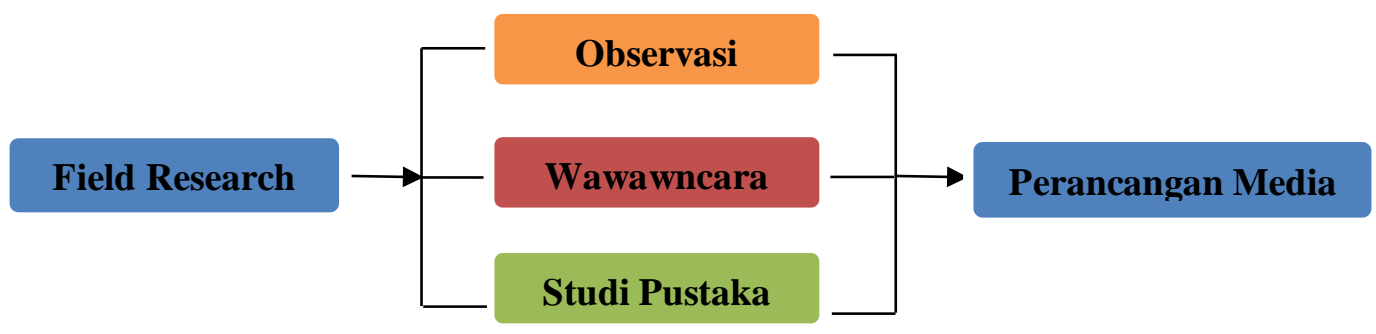

Gambar 1. Metode Penelitian

\section{LITERATURE REVIEW}

Penelitian yang dilakukan oleh Ramadhani, dkk (2018) ${ }^{[5]}$, yang berjudul "Preliminary Design pada Perancangan Merchandise Resmi Untuk Revenue Generated ITS Sebagai $P T N B H$ ". Penelitian ini membahas mengenai pengembangan produk Merchandise ITS untuk berbagai kegiatan ITS yang dibutuhkan dan dinilai sangat urgent. Produk yang dihasilkan yaitu T Shirt, Hoodie, Sweater, Tas Limited, Mug, Blazer dan Block Note.

Penelitian yang dilakukan oleh Arnada, dkk (2018) ${ }^{[6]}$, yang berjudul "Implementasi Multimedia Interaktif Pada Paud Nurul Hikmah Sebagai Media Pembelajaran”. Penelitian ini membahas mengenai penggunaan media pembelajaran berbasis teknologi pada Paud Nurul Hikmah yaitu animasi interaktif dengan tema pengenalan binatang dan abjad agar suasana belajar menjadi menarik dan materi yang disampaikan lebih mudah dipahami oleh siswa/i. Tidak hanya itu, terdapat stationery yang dibuat berupa amplop surat, kop surat, kartu nama dan Merchandise berupa mug (gelas).

Penelitian yang dilakukan oleh Maulani, dkk (2019) ${ }^{[7]}$, yang berjudul "Desain Promosi Branding Montsera Apartemen Menggunakan Media Komunikasi Visual Product Knowledge”. Penelitian ini membahas mengenai pembuatan produk knowledge bentuk cetakan dan juga template pada komputer yang digunakan untuk berbagai keperluan promosi branding Montsera Apartemen dalam memasarkan produk dan jasanya.

Penelitian yang dilakukan oleh Sunarya, dkk (2017) ${ }^{[8]}$, yang berjudul "Desain Merchandise Pada The Batu Hotel \& Villas". Penelitian ini membahas mengenai Pembuatan desain media Merchandise sebagai sarana promosi dan informasi yang akan diterima oleh masyarakat luas khususnya customer yang telah menginap The Batu Hotel \& Villas agar mendapatkan peningkatan citra agar lebih dikenal oleh masyarakat luas dan mendapatkan kesan yang baik.

Penelitian yang dilakukan oleh Aris, dkk (2017)[9], yang berjudul "Desain Merchandise Sebagai Penunjang Informasi dan Promosi SD Islam Miftahul Huda". Penelitian ini membahas mengenai pembuatan desain media Merchandise yang bertujuan untuk mempromosikan SD Islam Miftahul Huda sebagai bentuk meningkatkan daya jual sekolah terhadap masyarakat luas khususnya para orang tua yang ingin mendaftarkan anaknya. 


\section{HASIL DAN PEMBAHASAN}

\subsection{Konsep Perancangan}

Desain Merchandise Pada SMK Insan Madani Kabupaten Tangerang memiliki beberapa konsep perancangan, yaitu:

1. Perancangan Media

Sebagai bentuk strategi untuk menarik minat masyarakat luas khususnya calon siswa/i yang akan mendaftar sekaligus menjadi penunjang promosi pada SMK Insan Madani Kabupaten Tangerang dalam bentuk Merchandise, dibuatlah sebuah desain komunikasi visual yang di dalamnya terdapat unsur visualisasi yang memberikan kesan identitas sekolah, seperti logo, warna, typography dan Layout desain disesuaikan sedemikian rupa agar menjadi bagian dari media promosi SMK Insan Madani Kabupaten Tangerang sehingga terlihat menarik secara visual.

1. Desain Spanduk SMK Insan Madni Periode 14 Februari - 17 Februari 2020 dengan ukuran 200 x $100 \mathrm{~cm}$.

2. Desain Mug Gelas SMK Insan Madani Periode 19 Februari - 21 Februari 2020 dengan ukuran $8 \times 9 \mathrm{~cm}$.

3. Desain Kalender SMK Insan Madani Periode 1 Maret - 4 Maret 2020 dengan ukuran 29,7 x $42 \mathrm{~cm}$.

4. Desain Goodie Bag Tali SMK Insan Madani Periode 6 Maret - 10 Maret 2020 dengan ukuran $30 \times 40 \times 8 \mathrm{~cm}$.

5. Desain Jam Dinding SMK Insan Madani Periode 12 Maret - 15 Maret 2020 dengan ukuran $21 \times 29,7 \mathrm{~cm}$.

6. Desain Pin SMK Insan Madani Periode 20 Maret - 24 Maret 2020 dengan ukuran $5 \times 5 \mathrm{~cm}$.

7. Desain Stiker SMK Insan Madani Periode 27 Maret - 30 Maret 2020 dengan ukuran $3 \times 10 \mathrm{~cm}$.

8. Desain Gantungan Kunci SMK Insan Madani Periode 3 April - 7 April 2020 dengan ukuran 5 x $5 \mathrm{~cm}$.

9. Desain Pulpen SMK Insan Madani Periode 10 April - 14 April 2020 dengan ukuran 7 x $2,7 \mathrm{~cm}$.

10. Desain Amplop SMK Insan Madani Periode 16 April - 20 April 2020 dengan ukuran $21,5 \times 30 \mathrm{~cm}$.

2. Perencanaan Pesan (Konsep Kreatif)

Hasil desain yang telah dibuat selanjutnya telah diimplementasikan menjadi media yang nantinya digunakan sesuai dengan kebutuhan sebagaimana informasi yang didapatkan dari SMK Insan Madani Kabupaten Tangerang. Unsur yang terdapat pada media Merchandise tersebut telah mencapai tujuan dari konsep kreatif, dimana terdapat unsur teks (typography) untuk mendeskripsikan informasi mengenai masing-masing media dengan gaya bahasa yang mudah dipahami. Selanjutnya terdapat gambar yang bertujuan untuk menambah daya tarik dan sebagai identitas sekolah seperti menambahkan logo pada media desain dan terakhir adalah warna, yang menunjukan pesan, informasi tambahan dan identitas yang menggambarkan kepemilikan media Merchandise ini.

3. Perencanaan Visual

Perancangan media desain Merchandise sebagai media penunjang promosi pada SMK Insan Madani Kabupaten Tangerang ini dibuat dengan gaya visual bentuk visual yang memiliki nuansa baru beserta ide kreatif dalam perancangan desain dibuat semenarik mungkin dengan memadukan unsur teks (typography), gambar dan warna yang 
disesuaikan menjadi bentuk identitas baru dalam media promosi pada SMK Insan Madani Kota Tangerang. Adapun gaya penyajian grafis pada perancangan desain Merchandise ini dibuat lebih modern, clean dan nyaman untuk dilihat.

\subsection{Tujuan Kreatif Desain Media Komunikasi Visual}

Tujuan kreatif dalam pembuatan desain Merchandise pada SMK Insan Madani Kabupaten Tangerang adalah untuk menjadikan pembaruan media promosi pada media yang sebelumnya sudah ada dan kurang ter-update. Sehingga dibuatlah bentuk baru yang lebih menarik dengan informasi terbaru yang dapat meningkatkan kesan positif dari masyarakat luas khususnya calon siswa/i baru yang ingin mendaftar, sehingga diharapkan dapat meningkatkan citra sekolah dimata masyarakat serta meningkatkan perolehan jumlah siswa/i baru setiap tahunya.

\subsection{Layout Kasar}

Layout kasar adalah gambaran atau ide desain yang pada umumnya berupa seketsa dan nantinya digunakan sebagai panduan pada saat proses desain menggunakan aplikasi komputer agar hasil desain yang dibuat sesuai dengan gambaran yang diberikan pada Layout kasar. Pada tahap ini, masih dapat melakukan perubahan pada desain Berikut adalah Layout kasar yang telah dibuat:

- Spanduk dan Mug Gelas

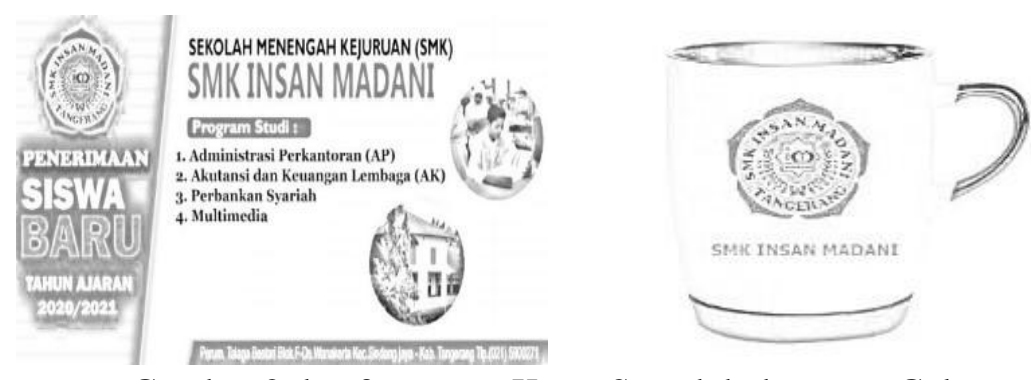

Gambar 2 dan 3. Layout Kasar Spanduk dan Mug Gelas

- Kalender dan Goodie Bag
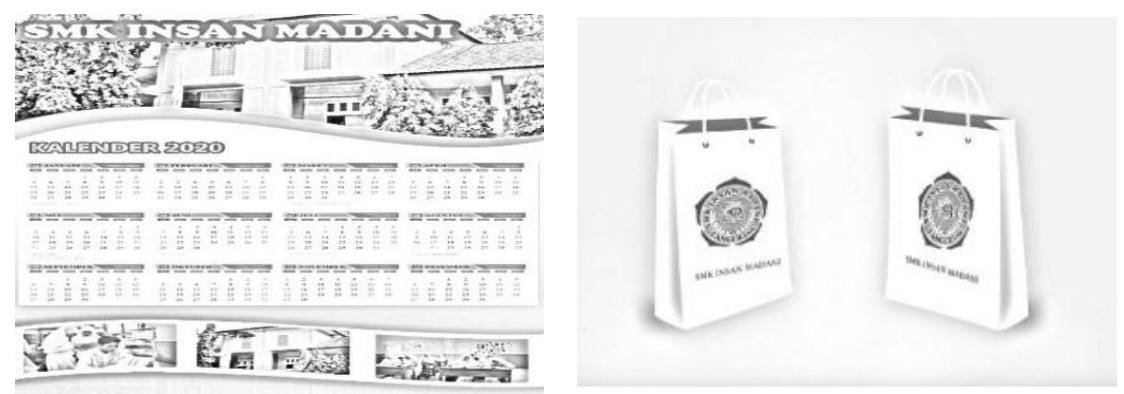

Gambar 4 dan 5. Layout Kasar Kalender dan Goodie Bag 
- Jam Dinding dan Pin

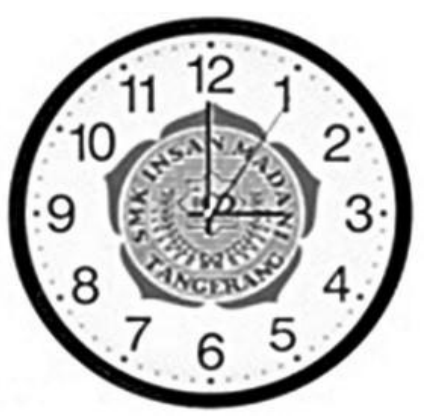

Gambar 6 dan 7. Layout Kasar Jam Dinding dan Pin

- Stiker dan Gantungan Kunci
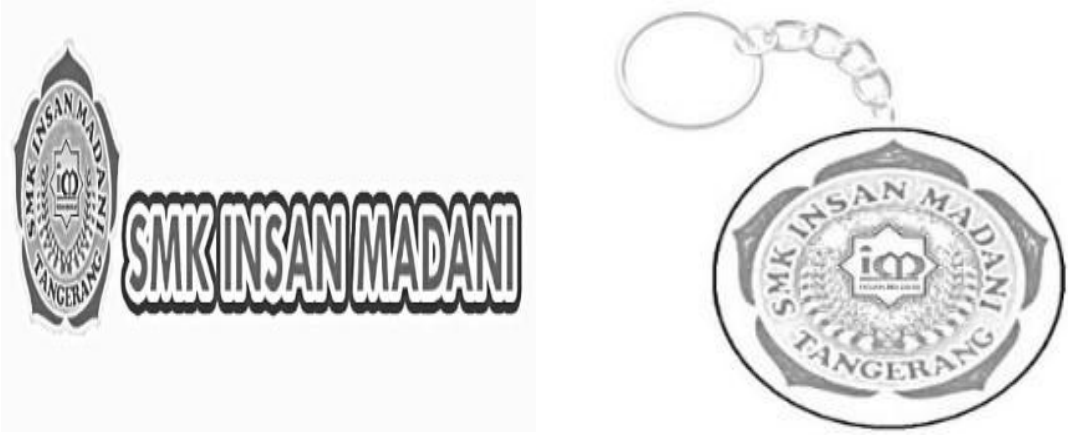

Gambar 8 dan 9. Layout Kasar Stiker dan Gantungan Kunci

- Pulpen dan Amplop
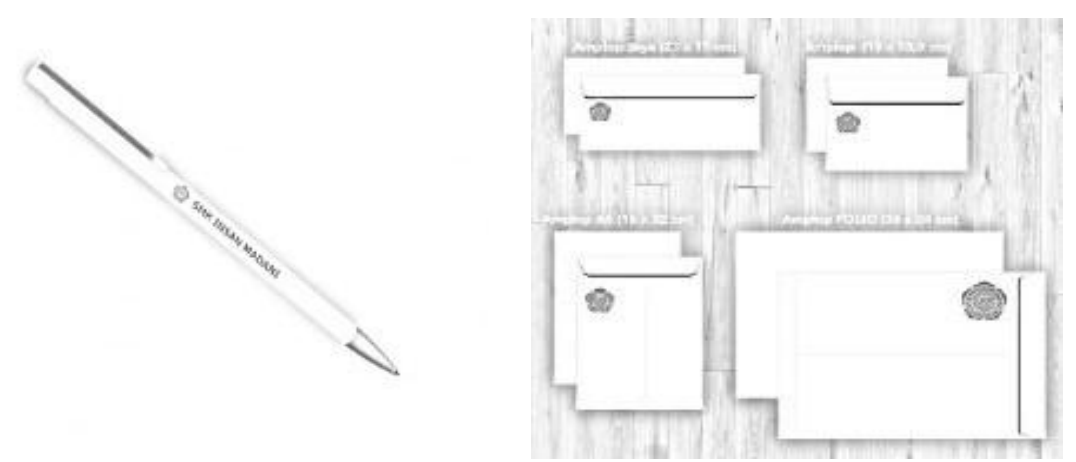

Gambar 10 dan 11. Layout Kasar Pulpen dan Amplop

\subsection{Layout Komprehensif}

Layout Komprehensif adalah proses desain menggunakan aplikasi komputer yang sudah melalui proses pembentukan Layout dan pewarnaan. Pada tahap desain sudah mendekati komposisi final akan tetapi masih dalam tahap revisi sesuai dengan permintaan yang diajukan oleh stakeholder. Proses pembuatan Layout Komprehensif ini menggunakan perangkat lunak Adobe Photoshop CC dan Adobe Ilustrator CC. Berikut adalah Layout Komprehensif. 
Print ISSN: 2723-1992

Online ISSN: 2723-200X
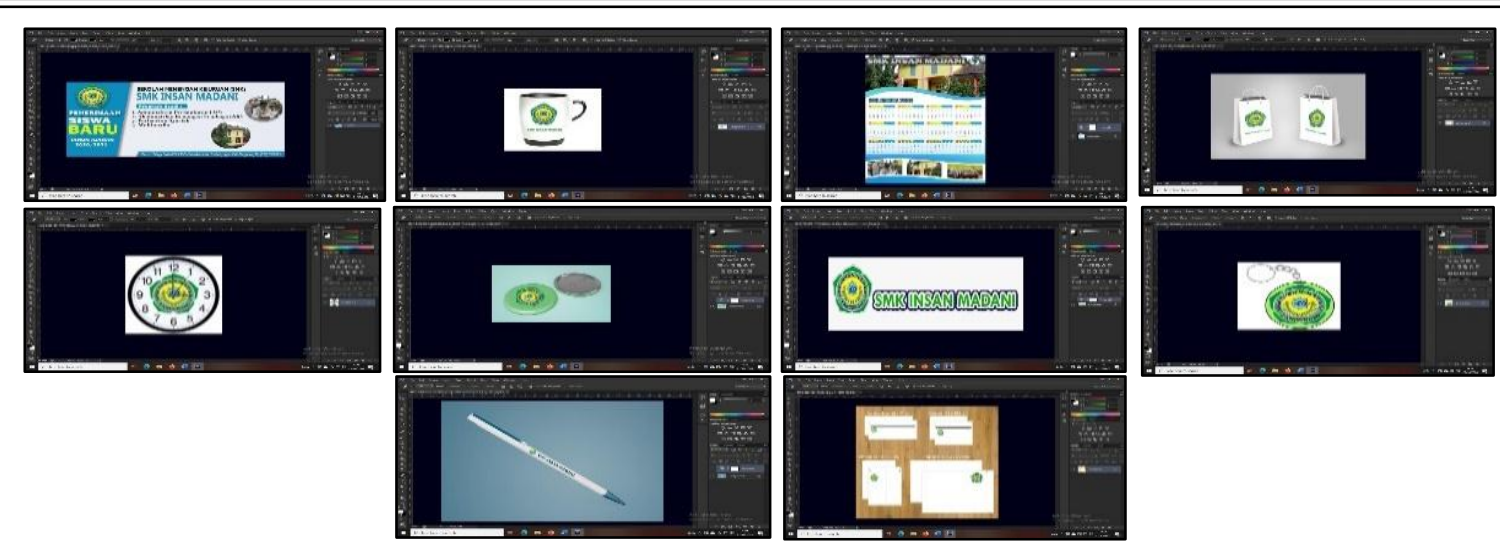

Gambar 12. Layout Komprehensif Merchandise SMK Insan Madani

\subsection{Final Artwork}

Final Artwork adalah hasil akhir (final) yang siap dicetak atau dibentuk untuk diedarkan secara luas berdasarkan kebutuhan penggunaannya setelah melalui proses desain yang terkomputerisasi seperti pembentukan Layout, pemberian teks, gambar dan warna. Berikut adalah Final Artwork Merchandise SMK Insan Madani Kabupaten Tangerang:

- Spanduk dan Mug Gelas

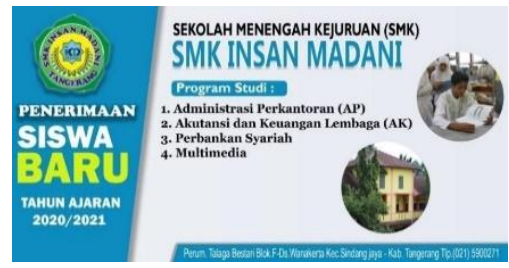

Gambar 13. Final Artwork Spanduk

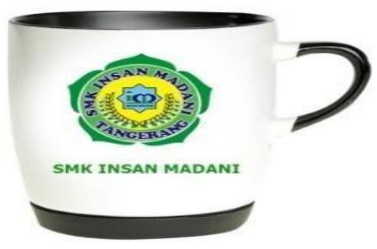

Gambar 14. Final Artwork Mug Gelas

Konsep desain Merchandise spanduk yang dibuat adalah menggunakan warna seperti, kuning, biru, putih, hitam dan abu-abu yang dipadukan dengan jenis font Cooper Black, Franklin Gothic Heavy, Gadugi, dan Arial. Sedangkan untuk konsep desain Merchandise mug gelas yang dibuat adalah menggunakan warna seperti putih, hitam dan hijau yang dipadukan dengan jenis font Tahoma dengan ukuran mug yaitu 8 x $9 \mathrm{~cm}$.

- Kalender dan Goodie Bag

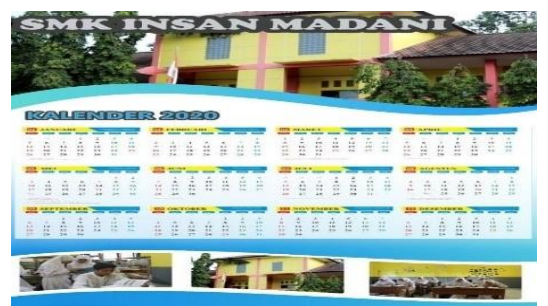

Gambar 15. Final Artwork

Kalender

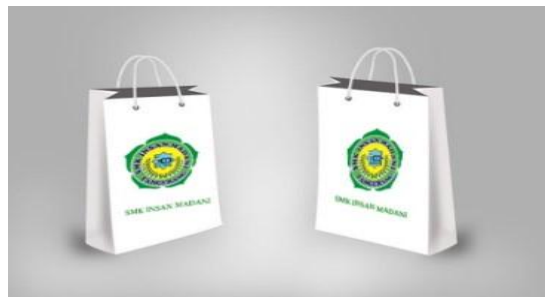

Gambar 16. Final Artwork Goodie Bag

Konsep desain Merchandise kalender yang dibuat adalah warna yang digunakan seperti biru, putih, abu-abu, kuning, hijau dan merah yang dipadukan dengan jenis font Microsoft Tai Le dan Cooper Black. Sedangkan konsep desain Merchandise goodie bag tali yang dibuat adalah menggunakan warna seperti putih dan hijau dengan background abu-abu yang dipadukan dengan jenis font Arial. 
- Jam Dinding dan Pin

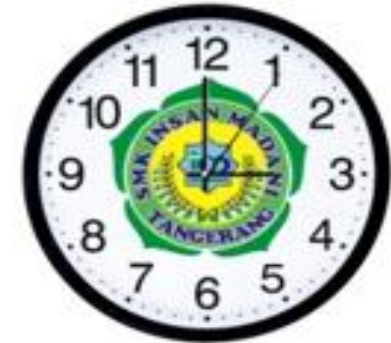

Gambar 17. Final

Artwork Jam Dinding

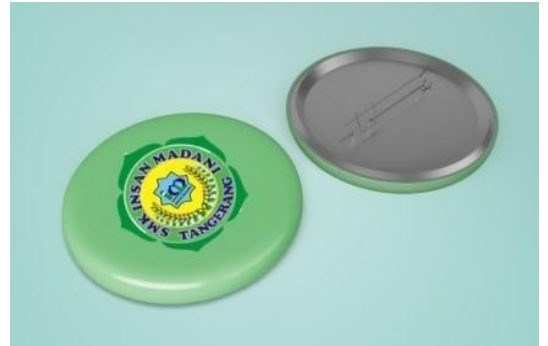

Gambar 18. Final Artwork

Pin

Konsep desain Merchandise jam dinding yang dibuat adalah menggunakan warna seperti putih dan hitam yang dipadukan dengan jenis font Tahoma. Sedangkan konsep desain Merchandise pin yang dibuat adalah menggunakan warna seperti hijau, hijau muda dan silver dengan tambahan gambar berupa logo sekolah SMK Insan Madani.

- Stiker dan Gantungan Kunci

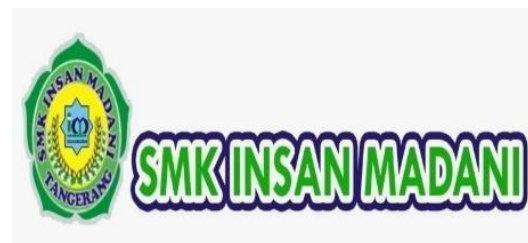

Gambar 19. Final Artwork Stiker

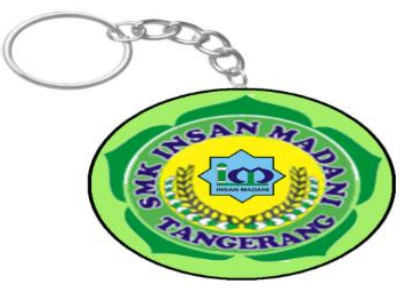

Gambar 20. Final Artwork Gantungan Kunci

Konsep desain stiker yang dibuat adalah menggunakan warna seperti biru, putih, hijau, kuning dan ungu yang dipadukan dengan jenis font TW Cen MT. Sedangkan konsep desain Merchandise gantungan kunci yang dibuat adalah menggunakan warna seperti putih, hijau, dan hitam dengan tambahan gambar berupa logo sekolah SMK Insan Madani.

- Pulpen dan Amplop

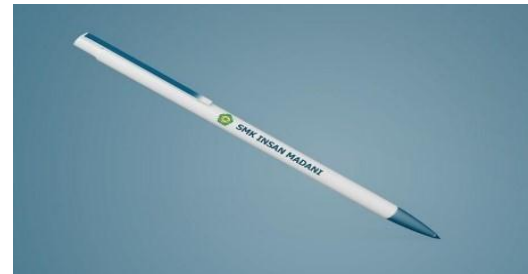

Gambar 21. Final Artwork

Pulpen

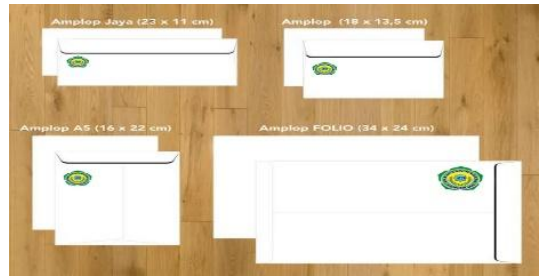

Gambar 22. Final Artwork

Amplop

Konsep desain Merchandise pulpen yang dibuat adalah menggunakan warna seperti biru, putih dan hijau pada warna logo yang dipadukan dengan jenis font Tahoma. Sedangkan konsep desain amplop yang dibuat adalah menggunakan warna seperti putih, hitam dan hijau dengan tambahan logo sekolah dan dipadukan dengan jenis font Comic Sans dengan ukuran amplop $21,5 \times 30 \mathrm{~cm}$. 


\section{KESIMPULAN}

Dengan adanya desain Merchandise ini, Media informasi sekaligus media promosi pada SMK Insan Madani Kabupaten Tangerang telah ter-update dan mengalami pembaruan sebagai strategi untuk memperkenalkan informasi identitas sekolah sebagai bentuk menguatkan daya tarik sekolah dimata masyarakat luas, khususnya calon siswa/i baru. Tidak hanya itu saja, pembuatan Merchandise seperti Spanduk, Mug Gelas, Kalender, Goodie Bag, Jam Dinding, Pin, Stiker, Gantungan Kunci, Pulpen dan Amplop ini sebagai bentuk apresiasi yang diberikan atas kepercayaan masyarakat luas yang sudah memilih SMK Insan Madani Kabupaten Tangerang sebagai tempat untuk menuntut ilmu dan menyelesaikan pendidikan bagi calon siswa/i baru.

\section{SARAN}

Dengan adanya media promosi dan informasi ini penulis menyarankan agar SMK Insan Madani Kabupaten Tangerang lebih luas lagi dalam memperkenalkan, media promosi dan informasi dengan menggunakan media cetak maupun elektronik. Disarankan pada SMK Insan Madani Kabupaten Tangerang agar program media promosi dan informasi selalu di update sesuai jadwal yang sudah ditentukan. Dan media promosinya semakin berinovasi. Penulis berharap akan ada penelitian selanjutnya dalam mengembangkan media promosi dan informasi yang telah ada dengan konsep dan penyajian yang lebih menarik audience. Sehingga setiap tahun jumlah calon mahasiswa dan calon mahasiswa semakin bertambah sesuai target yang diinginkan SMK Insan Madani.

\section{UCAPAN TERIMAKASIH}

Penulis mengucapkan terima kasih kepada pihak SMK Insan Madani Kabupaten Tangerang yang telah mengizinkan penulis untuk melakukan penelitian khususnya kepada Kepala Sekolah dan Guru-Guru yang telah memberikan dukungan kepada penulis sehingga penelitian ini bisa dilakukan dengan baik.

\section{DAFTAR PUSTAKA}

[1] Marpaung, Junierissa, 2018, Pengaruh Penggunaan Gadget Dalam Kehidupan, Jurnal KOPASTA, Vol.5, No.2, Batam, Universitas Riau Kepulauan.

[2] Tama, Adi Kusuma Widya, Maria Dingi Novena dan Sefty Lestari, 2017, Perancangan Merchandise Guna Menunjang Efektivitas Promosi", Journal Sensi Vol.3 No.1, Universitas Raharja, Tangerang.

[3] Andriyan, Wendy, Sindiawati, dan Ghina Puspita Kurnia, Desain Komunikasi Visual Sebagai Media Informasi Pada Kelurahan Kebon Besar Kota Tangerang. Bina Insani ICT Journal, Vol.7, No.1, Bekasi, Universitas Bina Insani.

[4] Idris, Syahril dan Lisa Amalia, 2020, Peningkatan Keterampilan Penggunaan Desain Grafis CorelDraw Di Kelurahan Wajo Baru Makassar, Jurnal Ilmiah Ecosystem Vol.20 No.1, Makassar, Universitas Bosowa.

[5] Ramadhani, Nugrahardi, Denny Indrayana Setyadi, Rabendra Yudistira Alamin dan Didit Prasetyo. Preliminary Design Pada Perancangan Merchandise Resmi Untuk Revenue Generated ITS Sebagai PTNBH, Jurnal Bahasa Rupa, Vol.1 No.2, STMIK STIKOM Indonesia, Denpasar. 
[6] Arnada, Elvara Zunia dan Ricky Widyananda Putra, 2018, Implementasi Multimedia Interaktif Pada Paud Nurul Hikmah Sebagai Media Pembelajaran. Jurnal IDEALIS, Vol.1 No.5, Universitas Budi Luhur, Jakarta.

[7] Maulani, Giandari, Henderi, dan Rahmah Diana, 2019, Desain Promosi Branding Montsera Apartemen Menggunakan Media Komunikasi Visual Product Knowledge, SENSITIf: Seminar Nasional Sistem Informasi dan Teknologi Informasi 2019, STMIK Dipanegara, Makassar.

[8] Sunarya, Lusyani, Meliyana dan Titik Nofitasari, 2017, Desain Merchandise Pada The Batu Hotel \& Villas, Cogito Smart Journal Vol.3 No.1, Sulawesi Utara, Universitas Klabat.

[9] Aris, Chris Syahnaz dan Siti Mariah Ulfah, 2017, Desain Merchandise Sebagai Penunjang Informasi dan Promosi SD Islam Miftahul Huda, SENSI Journal Vol.3 No.2, Tangerang, Universitas Raharja. 